\title{
Iron-Catalyzed Oxidative Homo-Coupling of Aryl Grignard Reagents
}

Takashi Nagano and Tamio Hayashi*

Department of Chemistry, Graduate School of Science, Kyoto University, Sakyo, Kyoto 606-8502, Japan

\section{Supporting Data}

General. All anaerobic and/or moisture sensitive manipulations were carried out with standard Schlenk techniques under predried nitrogen or with glovebox techniques under prepurified argon. Tetrahydrofuran and diethyl ether were distilled from sodium benzophenone ketyl under nitrogen prior to use. The Grignard reagents 1a-1f were prepared in dry diethyl ether from the corresponding commercially available aryl bromides by the standard method. 2-Methyl-1-naphthylmagnesium bromide (1h) was prepared in benzene/ $\mathrm{Et}_{2} \mathrm{O}$ according to the literature procedure. ${ }^{1}$ 2-Methoxy-6-methylbromobenzene, which is the precursor of the Grignard reagent $\mathbf{1 g}$, was prepared according to the literature method. $^{2}$ Methoxymethyl phenyl ether $(4)^{3}$ and 5,5-dimethyl-2-phenyl-2-oxazoline $(6)^{4}$ were prepared according to the literature methods. Melting points were uncorrected. NMR spectra were recorded on a JEOL JNM LA500 spectrometer $\left({ }^{1} \mathrm{H}, 500 \mathrm{MHz} ;{ }^{13} \mathrm{C}, 125 \mathrm{MHz}\right)$. ${ }^{1} \mathrm{H}$ and ${ }^{13} \mathrm{C}$ chemical shifts are reported in ppm downfield of internal tetramethylsilane.

General procedure for the iron-catalyzed homo-coupling. To a refluxing solution of $\mathrm{FeCl}_{3}(0.0026 \mathrm{mmol})$ and 1,2-dichloroethane $(0.62 \mathrm{mmol})$ in diethyl ether $(4 \mathrm{~mL})$ was added a Grignard reagent $(0.52 \mathrm{mmol})$ and the reaction mixture was refluxed for $1 \mathrm{~h}$. The reaction was quenched by addition of aqueous $\mathrm{HCl}(1 \mathrm{~N})$. The organic layer was separated and the aqueous layer was extracted by ether. The combined organic layers were dried over anhydrous magnesium sulfate. All volatiles were removed under reduced pressure and the residue was chromatographed on silica gel. Spectroscopic and analytical data of the new biaryls are as follows;

2,2 -dimethoxy-6,6 -dimethyl-1,1 -biphenyl (3g). White solid. Mp 84-85 ßC. ${ }^{1} \mathrm{H}$ NMR

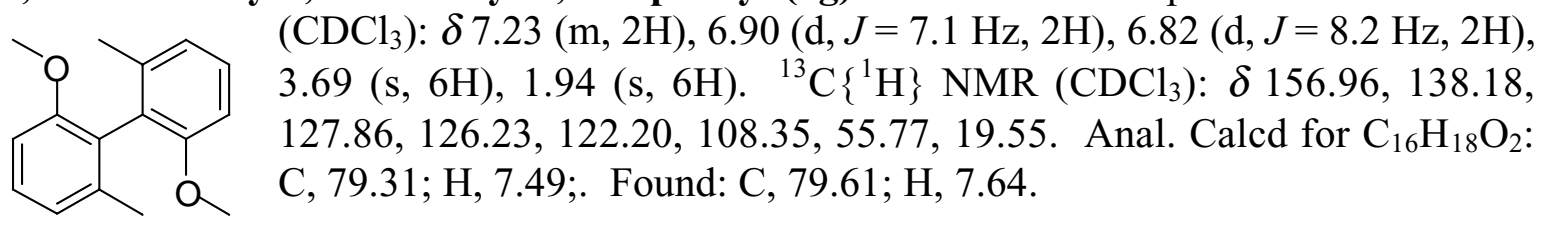

Procedure for directed ortho-metallation followed by homocoupling reaction

Synthesis of 5. To a solution of methoxymethyl phenyl ether (4) (200 mg, $1.45 \mathrm{mmol})$ in $\mathrm{Et}_{2} \mathrm{O}(2.0 \mathrm{~mL})$ was added $n$-BuLi $(1.54 \mathrm{M}$ in hexane, $1.04 \mathrm{~mL}, 1.60 \mathrm{mmol})$ at room temperature and the resulting solution was stirred for 3 . The mixture was added to a solution of anhydrous $\mathrm{MgBr}_{2}$, which was freshly prepared by treatment of $\mathrm{Mg}(53.0 \mathrm{mg}$, $2.18 \mathrm{mmol})$ with 1,2-dibromoethane $(175 \mu \mathrm{L}, 2.03 \mathrm{mmol})$ in $\mathrm{Et}_{2} \mathrm{O}(2.0 \mathrm{~mL})$, and the resulting yellow solution was stirred at room temperature for $0.5 \mathrm{~h}$. To this was added a solution of $\mathrm{FeCl}_{3}(12 \mathrm{mg}, 0.074 \mathrm{mmol})$ and 1,2-dichloroethane $(172 \mu \mathrm{L}, 2.18 \mathrm{mmol})$ in 
$\mathrm{Et}_{2} \mathrm{O}(2.0 \mathrm{~mL})$, and the reaction mixture was refluxed for $15 \mathrm{~h}$ before it was quenched with water. The organic layer was separated and the aqueous layer was extracted with $\mathrm{Et}_{2} \mathrm{O}$. The combined organic layers were dried over anhydrous $\mathrm{K}_{2} \mathrm{CO}_{3}$. All volatiles were removed under reduced pressure and the residue was chromatographed on silica gel $($ Hexane/EtOAc $=9 / 1)$ to give 2,2 -bis(methoxymethoxy)biphenyl (5) ${ }^{5}(220 \mathrm{mg}, 71 \%$ ).

Synthesis of 7. To a solution of 2-phenyl-4,4-dimethyl-2-oxazoline (6) (200 mg, 1.14 $\mathrm{mmol})$ in $\mathrm{Et}_{2} \mathrm{O}(2.0 \mathrm{~mL})$ was added $s-\mathrm{BuLi}(1.01 \mathrm{M}$ in hexane/cyclohexane, $1.24 \mathrm{~mL}, 1.25$ $\mathrm{mmol})$ at $-78 ß \mathrm{C}$ and the resulting solution was stirred at that temperature for $1.5 \mathrm{~h}$. The mixture was allowed to warm to $0 \AA \mathrm{C}$ and the solution was stirred at $0 ß \mathrm{C}$ for $1.5 \mathrm{~h}$. This was added to a solution of anhydrous $\mathrm{MgBr}_{2}$, which was freshly prepared by treatment of $\mathrm{Mg}$ (42 mg, $1.71 \mathrm{mmol})$ with 1,2-dibromoethane $(138 \mu \mathrm{L}, 1.60 \mathrm{mmol})$ in $\mathrm{Et}_{2} \mathrm{O}(2.0 \mathrm{~mL})$, and the resulting yellow solution was stirred at room temperature for $0.5 \mathrm{~h}$. To this was added a solution of $\mathrm{FeCl}_{3}(9.0 \mathrm{mg}, 0.055 \mathrm{mmol})$ and 1,2-dichloroethane $(135 \mu \mathrm{L}, 1.71$ $\mathrm{mmol})$ in $\mathrm{Et}_{2} \mathrm{O}(2.0 \mathrm{~mL})$, and the reaction mixture was refluxed for $15 \mathrm{~h}$ before it was quenched with water. The organic layer was separated and the aqueous layer was extracted by ether. The combined organic layers were dried over anhydrous $\mathrm{Na}_{2} \mathrm{SO}_{4}$. All volatiles were removed under reduced pressure and the residue was purified with preparative TLC on silica gel (hexane/ $\mathrm{Et}_{2} \mathrm{O}=1 / 1$ ) to give 2,2 -bis(4,4-dimethyl-2-oxazolin-2-yl)biphenyl $(7)^{6}(124 \mathrm{mg}, 63 \%)$.

NMR Spectra. NMR spectra for known $\left(\mathbf{3 a},{ }^{7} \mathbf{3 b},{ }^{7} \mathbf{3 c},{ }^{8} \mathbf{3 d},{ }^{7} \mathbf{3 e},{ }^{9} \mathbf{3 f},{ }^{7} \mathbf{3 h},{ }^{10} \mathbf{5},{ }^{5}\right.$ and $\left.\mathbf{7}^{6}\right)$ and new $(\mathbf{3 g})$ biaryls are given in pp S3-S13.

\section{References}

(1) Miyano, S.; Okada, S.-i.; Suzuki, T.; Handa, S.; Hashimoto, H. Bull. Chem. Soc. Jpn. 1986, 59, 2044.

(2) Hall, D. M.; Insole, J. M. J. Chem. Soc., Perkin Trans. 2 1972, 1164.

(3) Hasegawa, T.; Yamamoto, H. Synthesis 2003, 1177.

(4) Meyers, A. I.; Temple, D. L.; Haidukewych, D.; Mihelich, E. D. J. Org. Chem. 1974, 39, 2787.

(5) Zhang, H.-C.; Huang, W.-S.; Pu, L. J. Org. Chem. 2001, 66, 481.

(6) Yang, D.; Yip, Y.-C.; Wang, X.-C. Tetrahedron Lett. 1997, 38, 7083.

(7) Koza, D. J.; Carita, E. Synthesis 2002, 2183.

(8) Bock, B.; Kuhr, M.; Musso, H. Chem. Ber. 1976, 109, 1184.

(9) Hennings, D. D.; Iwama, T.; Rawal, V. H. Org. Lett. 1999, 1, 1205.

(10) Hayashi, T.; Hayashizaki, K.; Kiyo, T. J. Am. Chem. Soc. 1988, 110, 8153. 


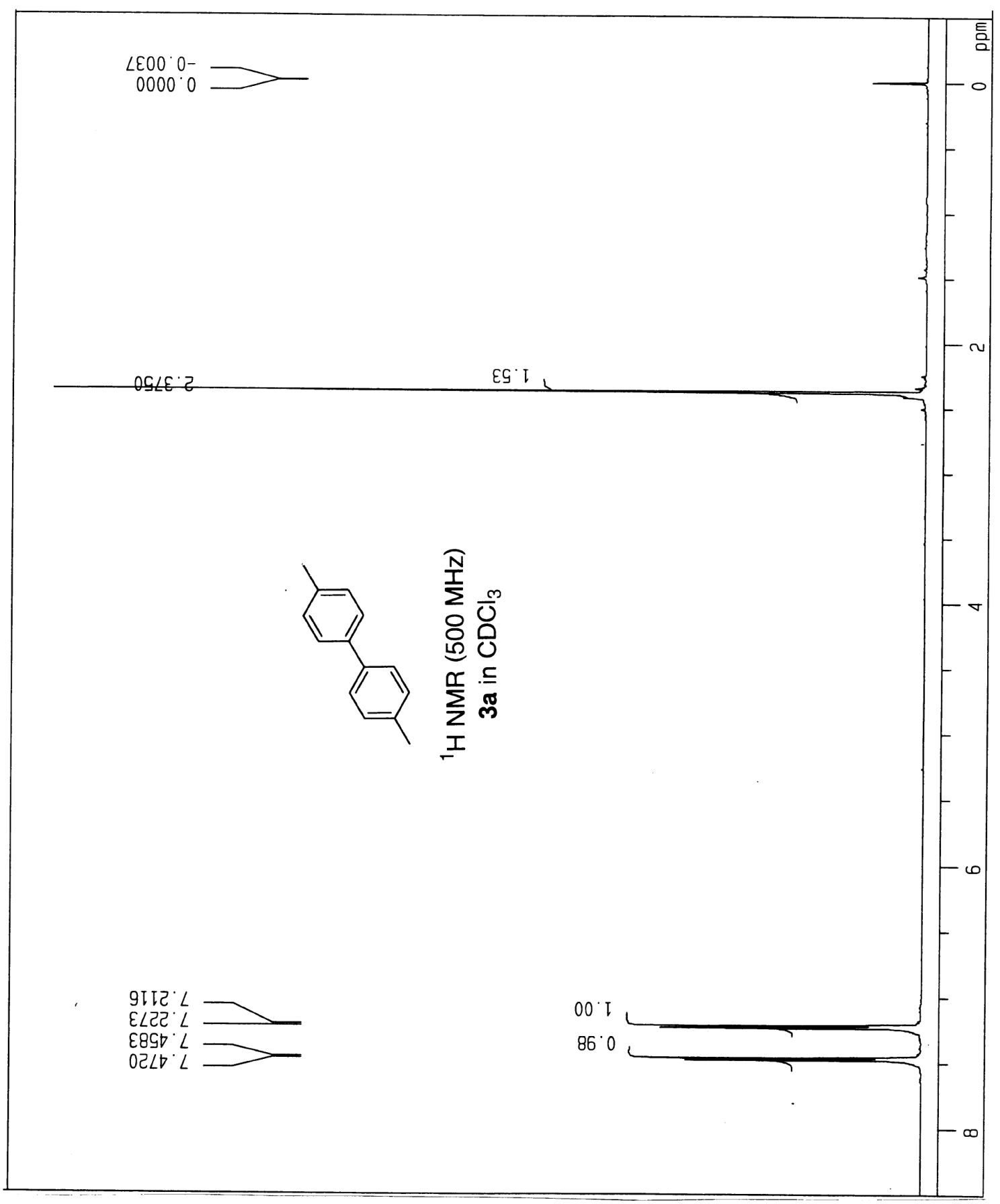




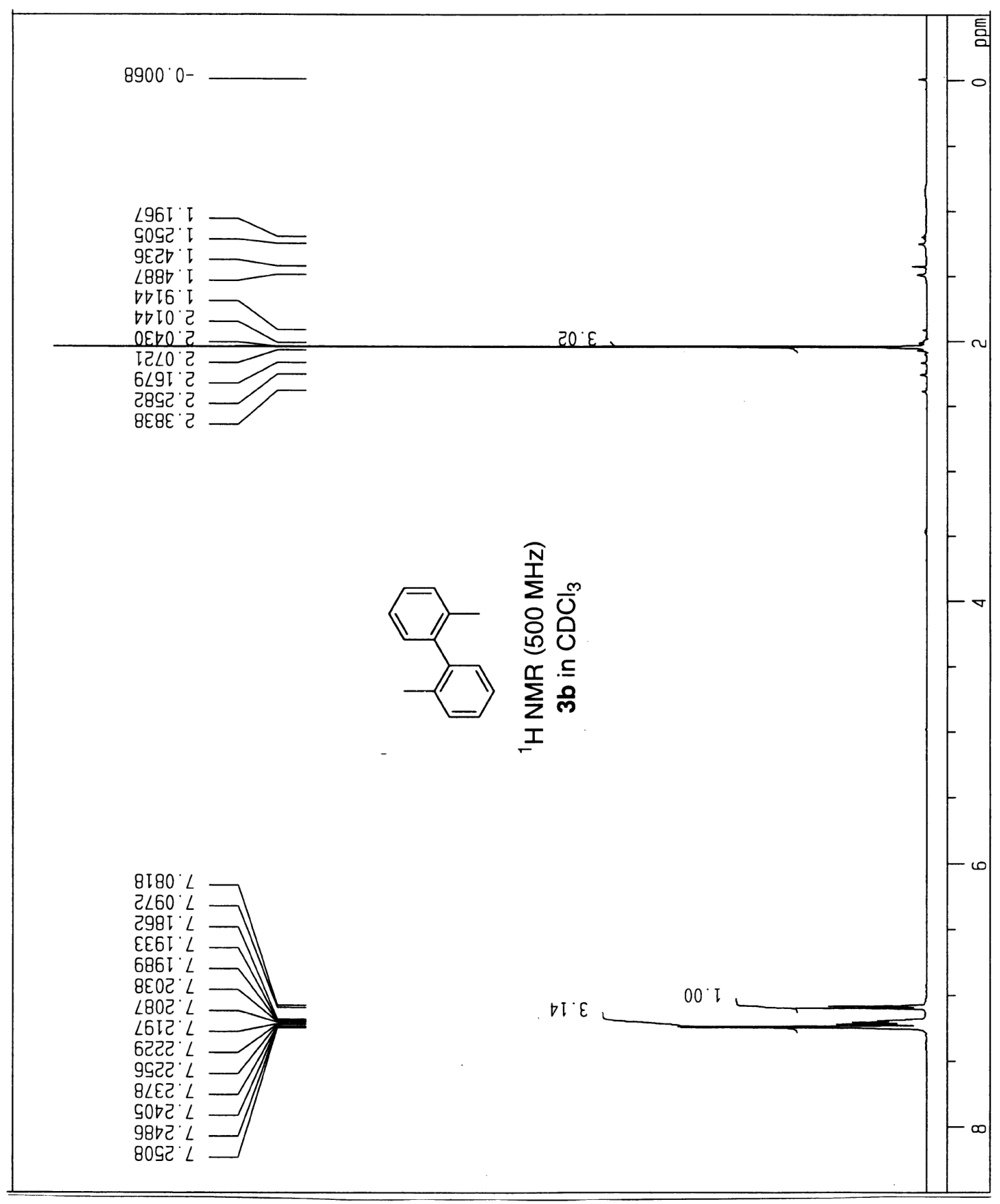




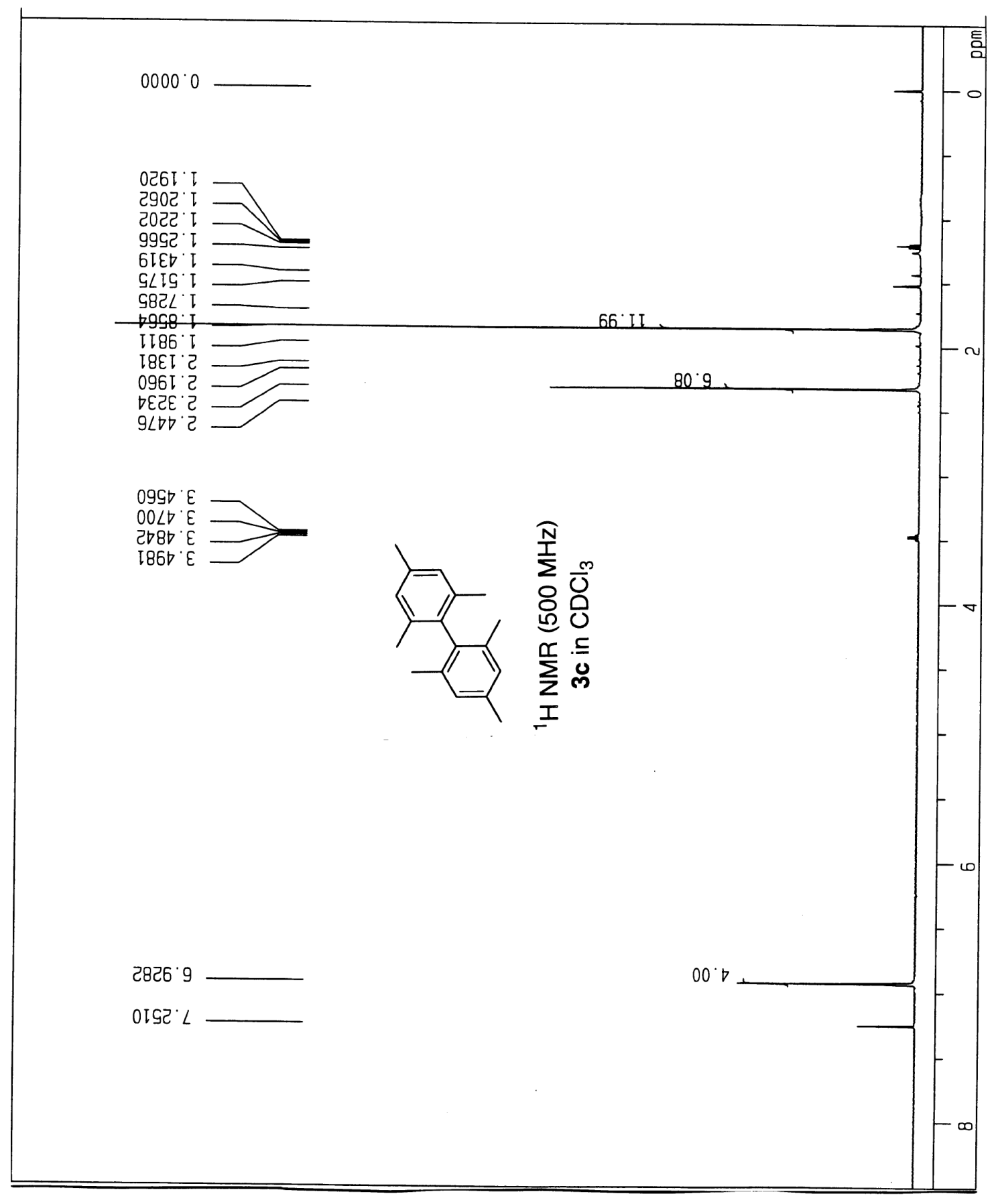




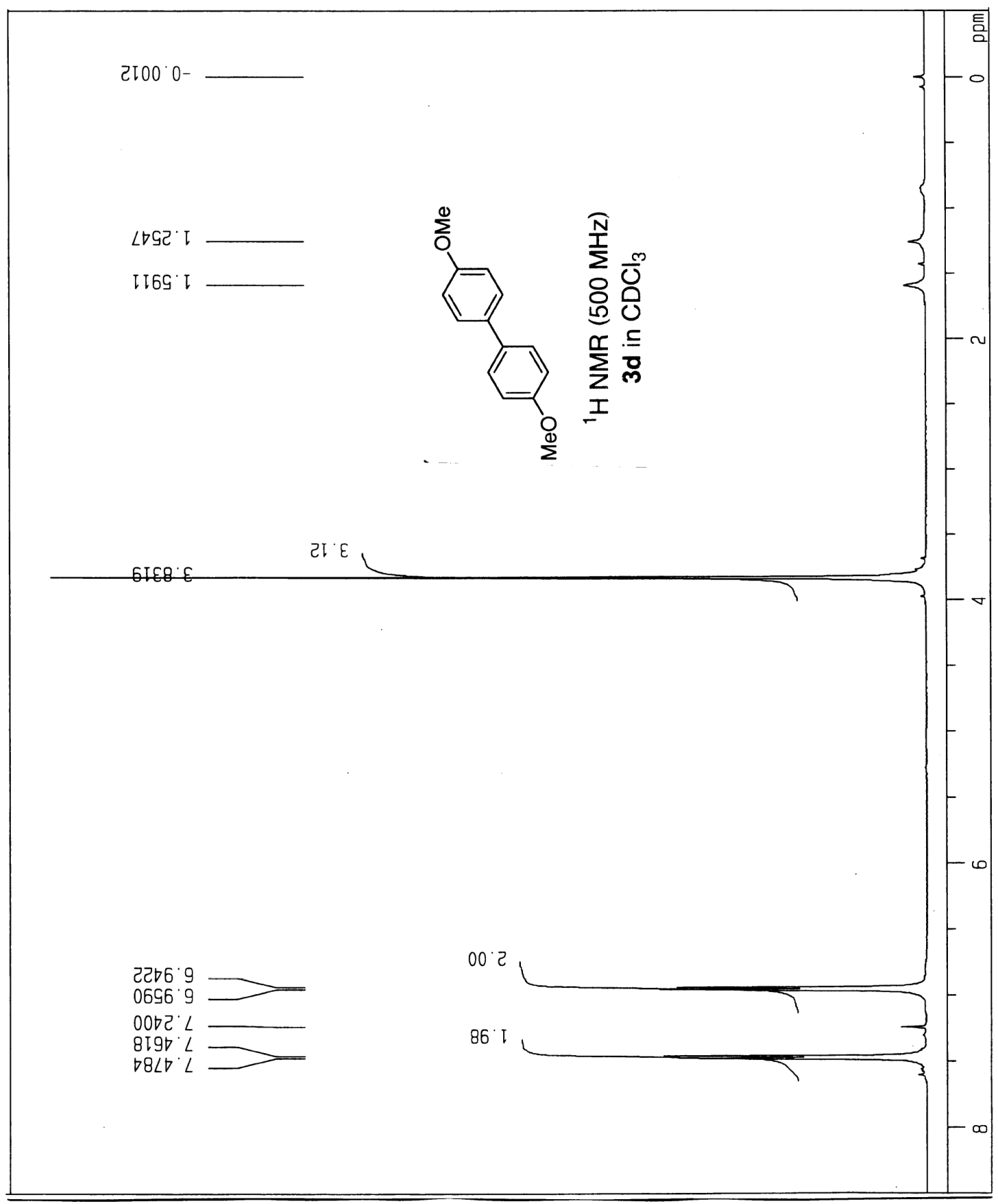




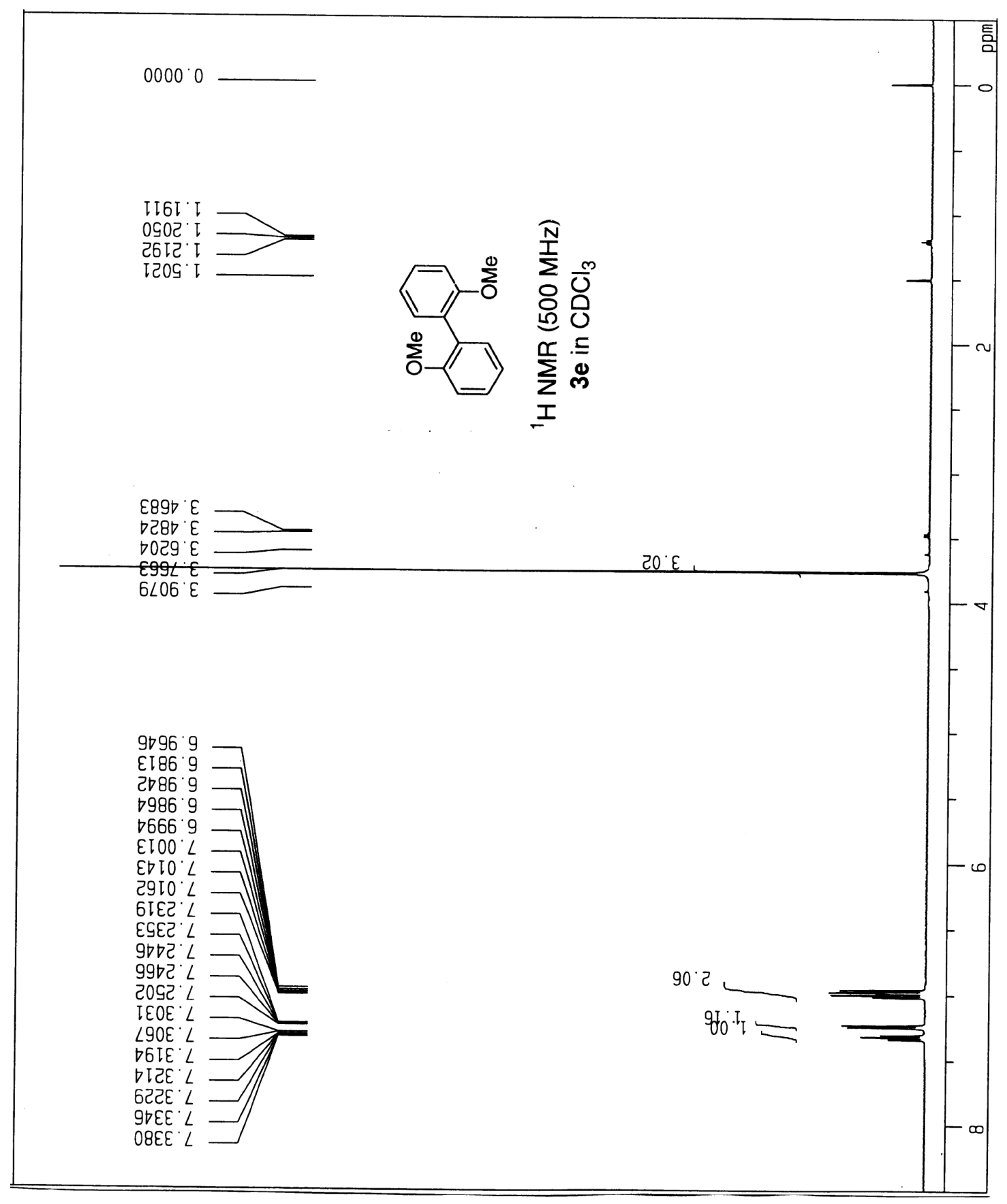




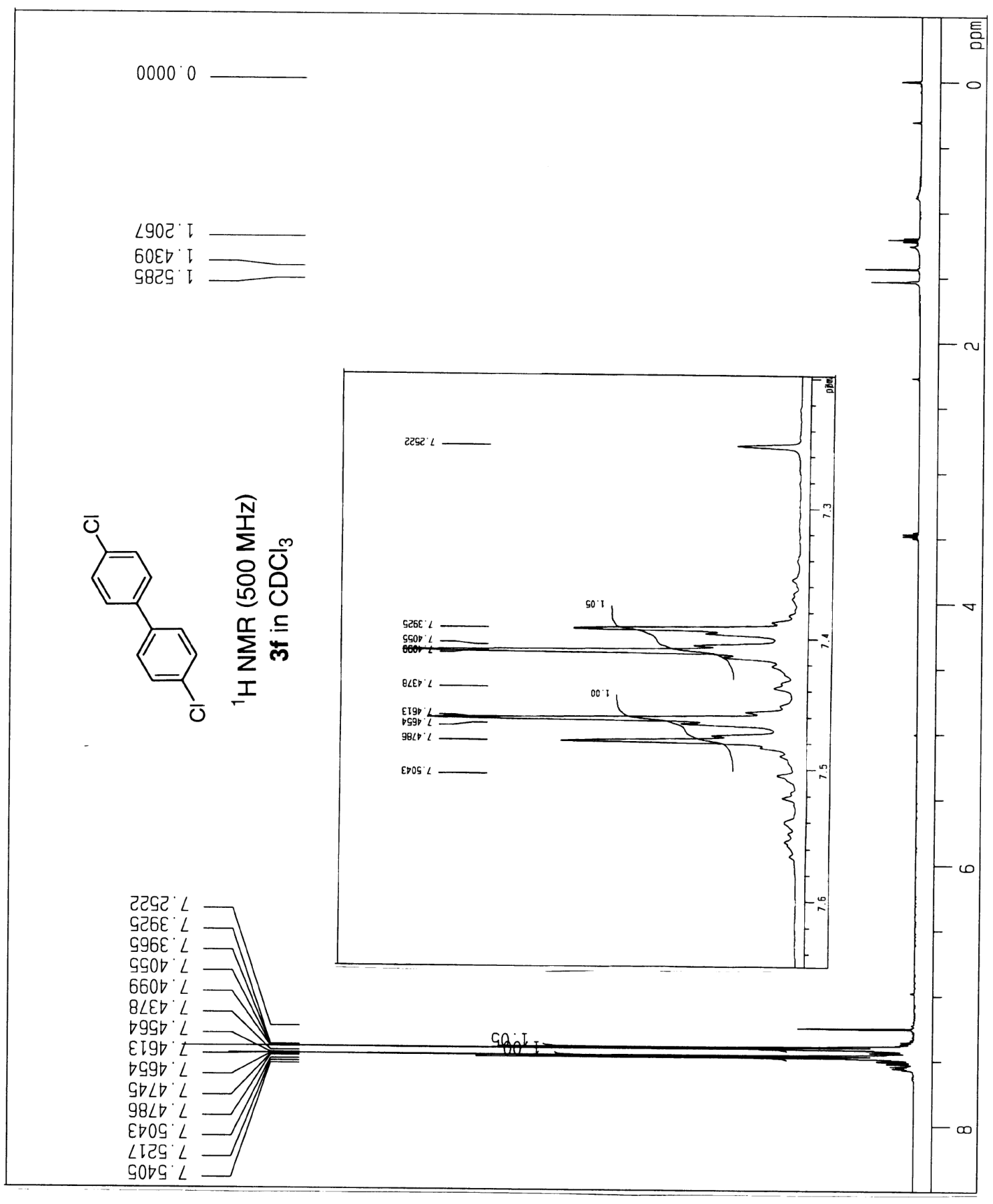




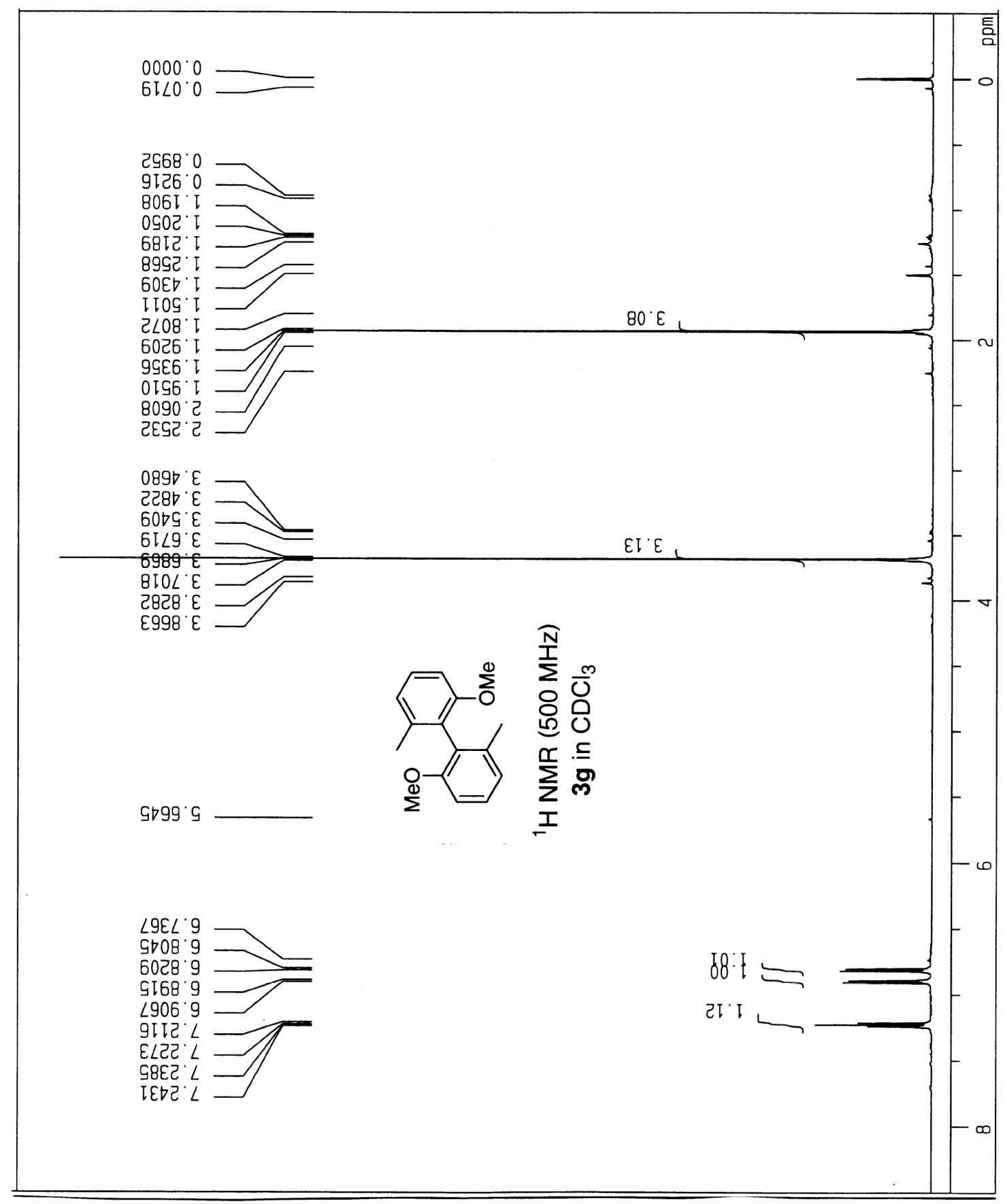




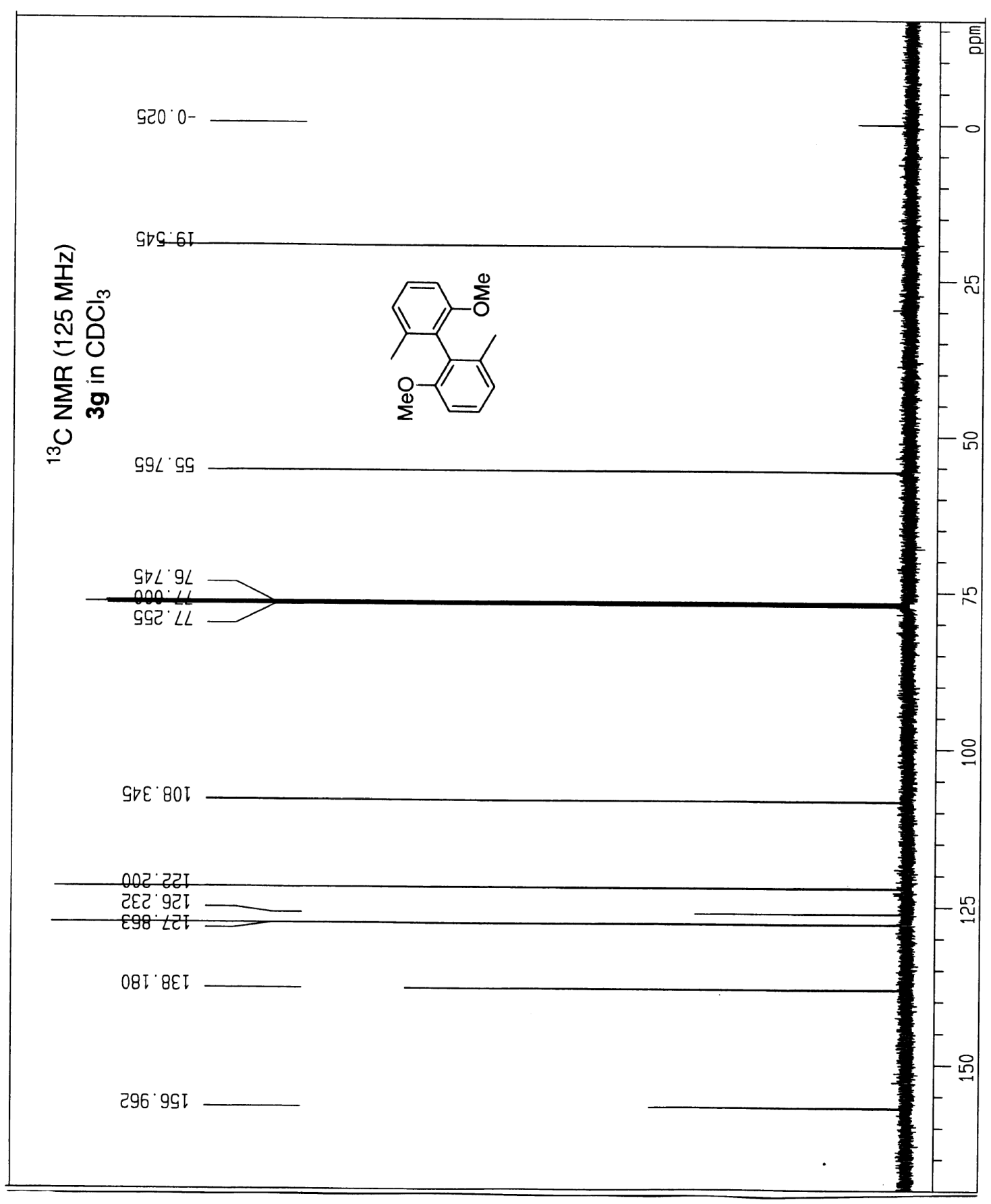




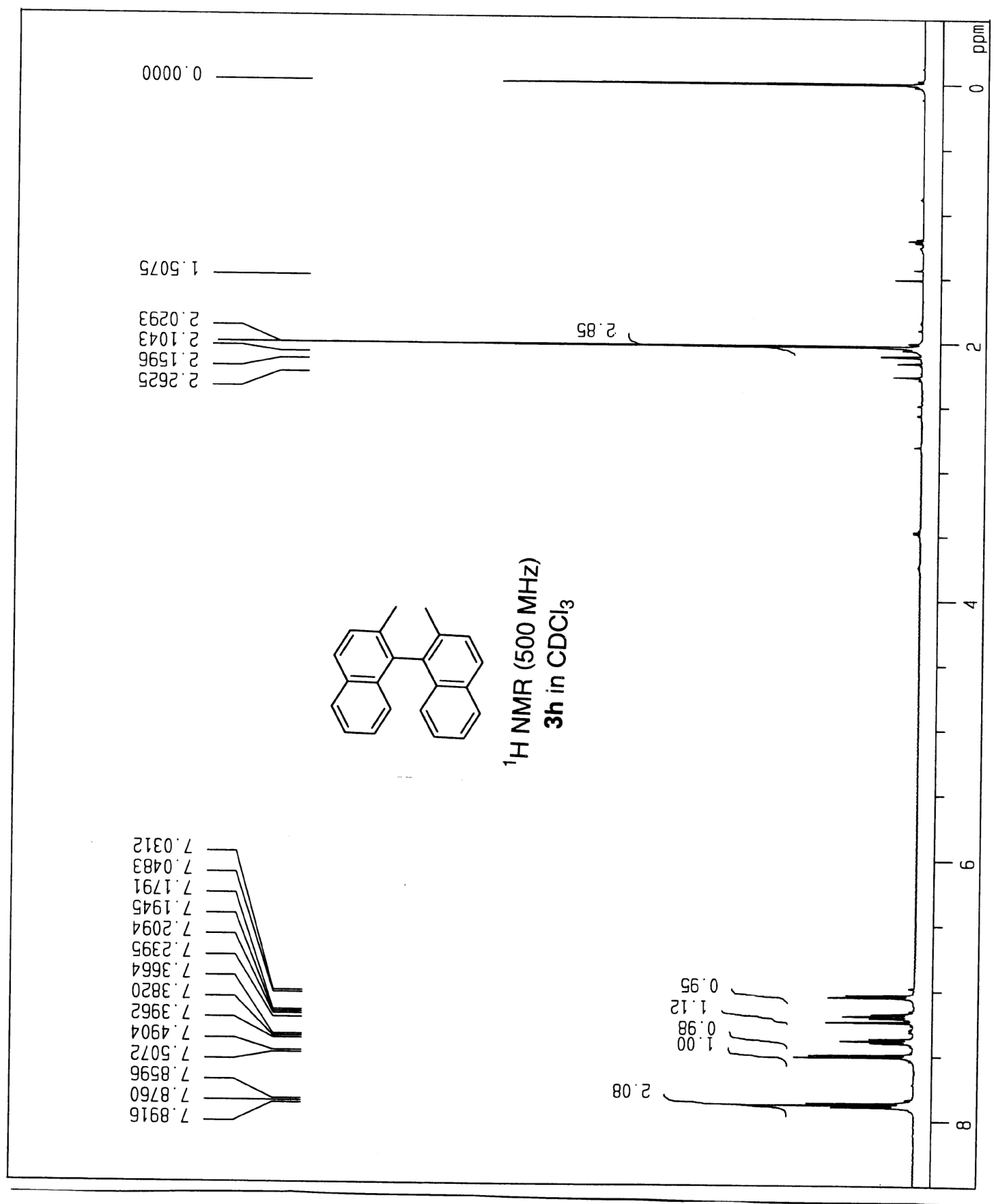




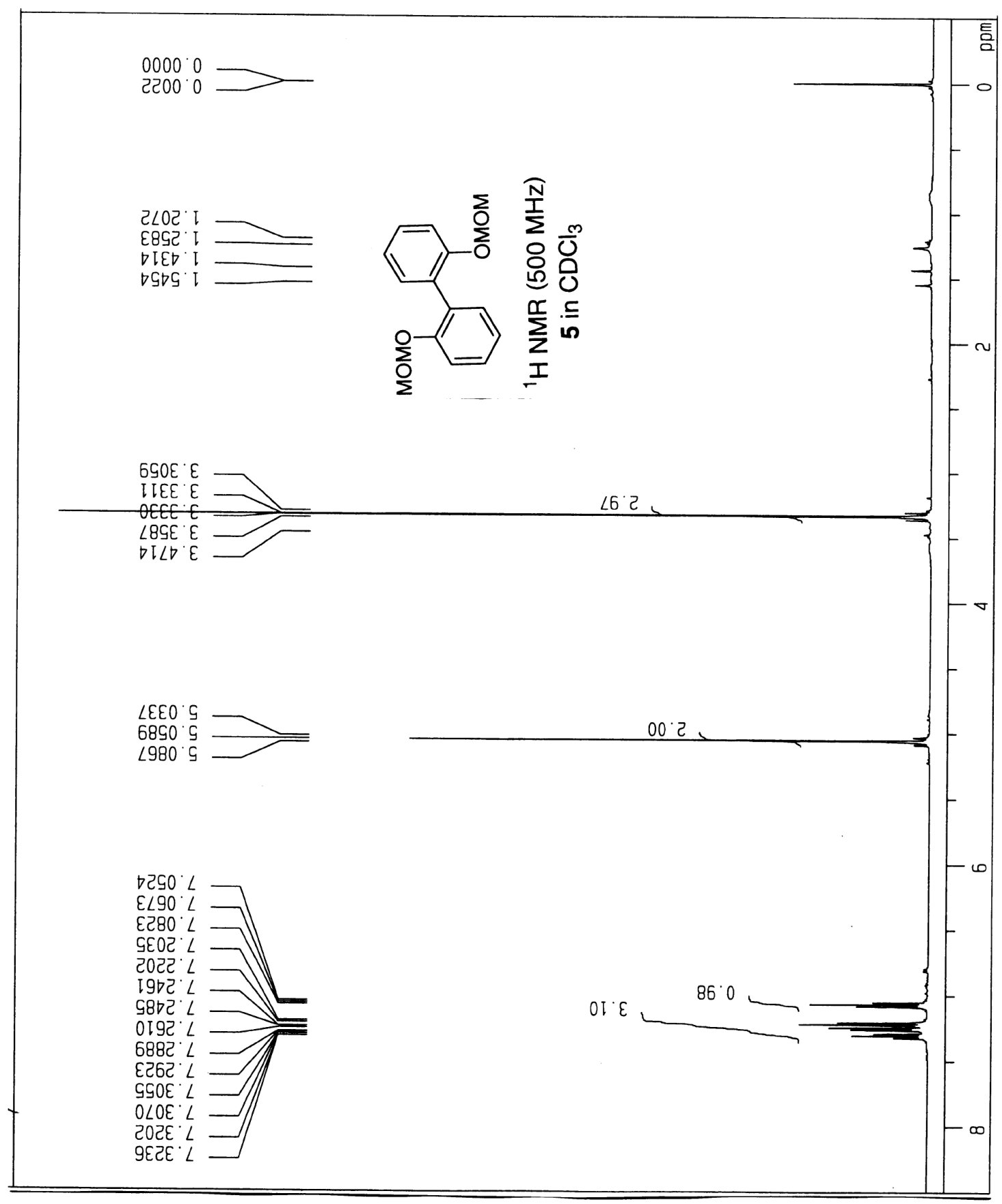




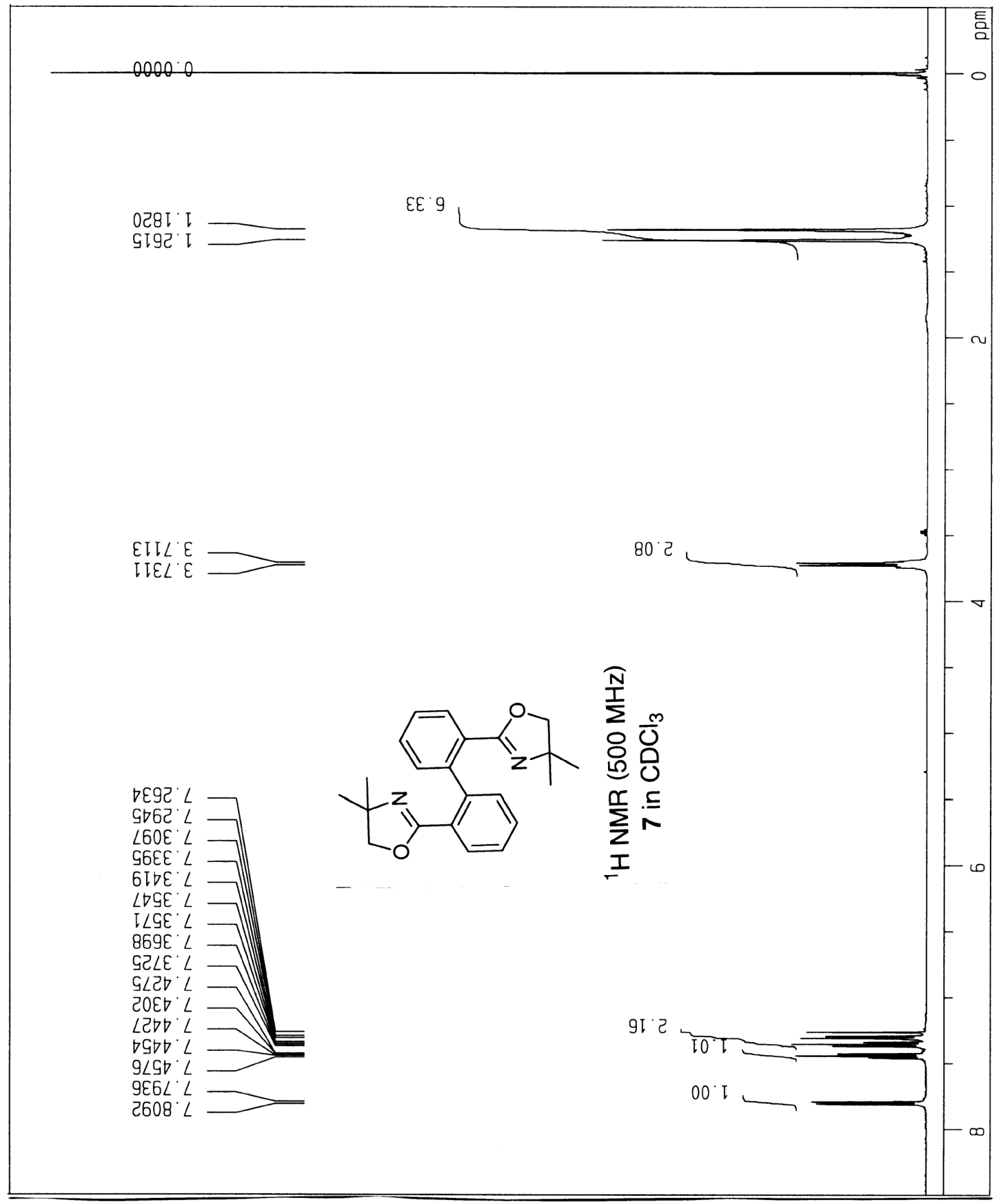

